\title{
ALTERIDAD, MIGRACIONES Y RACISMO EN REDES SOCIALES VIRTUALES: UN ESTUDIO DE CASO EN FACEBOOK
}

\author{
Otherness, migrations and racism inside virtural social networks: \\ a case of study on Facebook
}

\begin{abstract}
Resumen. El objeto teórico de estudio de este trabajo son las representaciones de alteridad sobre las migraciones y las nuevas lógicas de funcionamiento del racismo en Facebook, a través de un estudio de caso concreto. La pregunta de investigación es si presentan características particulares dichas representaciones y lógicas de funcionamiento del racismo, en el contexto estudiado, al ser vehiculadas a través de redes sociales virtuales. Para ello se ha procedido a través un diseño metodológico basado en el análisis de contenido. Los resultados apuntan a un recrudecimiento de los discursos racistas a través de estos medios sociales, en comparación con los discursos que podemos encontrar en los medios de comunicación de masas tradicionales.
\end{abstract}

Palabras clave: racismo; migraciones; redes sociales virtuales; Facebook.

Abstract. The theoretical object of this research is the representations of otherness about migrants and the new logics of how racism works on Facebook, through a specific case study. The research question is whether particular representations and logics of the functioning of racism have particular characteristics, in the context studied, by being conveyed through virtual social networks. The methodology has been content analysis. The results point out to a recrudescence of the racist discourses conveyed through these social media, in comparison with the discourses that can be found in the traditional mass media.

Keyword: racism; migrations; virtual social network; Facebook.

Instituto de Migraciones, Departamento de Antropología Social, Universidad de Granada. Granada, España. 


\section{Introducción ${ }^{1}$}

Podemos acercarnos al estudio de las tecnologías de la información y la comunicación de dos formas distintas: en tanto que objetos de estudio en sí mismos; o en tanto que medios/contextos para abordar otros objetos de estudio. Este trabajo ${ }^{2}$ se sitúa entre los segundos, haciendo uso -en este caso- de las redes sociales virtuales (en adelante RSV) para reflexionar sobre representaciones del fenómeno migratorio y sobre lógicas de funcionamiento de los discursos racistas en las mismas ${ }^{3}$.

El uso de las tecnologías de la información en la investigación en Ciencias Sociales -como parte de lo que se conoce como las "humanidades digitales" (Rodríguez, 2013; Romero, 2014)- es una cuestión imperativa en el momento actual para conocer sobre fenómenos y problemas sociales que, sin bien, existen independientemente de estas, adoptan una forma nueva con las mismas. Ello sucede con la inmigración, en tanto que fenómeno social; y con el racismo en tanto que problema social asociado en el momento actual de manera muy fuerte a las migraciones, de tal forma que podemos hablar de un racismo anti-inmigrante.

\section{La investigación sobre racismo en redes sociales virtuales}

Existen numerosos estudios sobre la imagen de la inmigración y el racismo en los medios de comunicación de masas tradicionales (Granados, 2013; Martínez, 2013; Van Dijk, 2009), pero no sucede lo mismo en los medios de comunicación sociales. Igual ocurre con otras temáticas y objetos teóricos de estudio. Hine (2004) en su pionera obra "Etnografía virtual" se preguntaba si lo virtual era algo distinto de lo real, se preguntaba por cómo las personas elaboraban y experimentaban sus identidades -las relaciones de alteridad, añadiría yo- en uno y otro escenario, y las relaciones que podían existir entre los procesos de identificación -y otrerización- que acontecen en ambos contextos. Con estas preguntas podemos iniciar una reflexión acerca de cómo puede afectar internet al desarrollo de relaciones sociales, en tanto que ha supuesto un cambio de paradigma de los procesos de información y comunicación.

Las características (que algunos ven en forma de "ventajas comunicacionales") de las RSV podrían arrojar luz sobre esta cuestión y orientarnos para encontrar respuestas al respecto. Es sabido, y asumido por la comunidad científica, que el racismo se comporta de forma distinta en

\footnotetext{
1 Agradezco a las profesoras Raquel Martínez Chicón y María Rubio Gómez la revisiones realizadas al presente artículo. Así mismo agradezco a la investigadora Ouafaa Bouachra Outmani sus aportaciones críticas en las primeras fases de este trabajo.

2 Este trabajo se inserta dentro del proyecto europeo "Multilevel Governance of Cultural Diversity in a Comparative Perspective: EU-Latin America (GOVDIV)", International Research Staff Exchange Scheme - Marie Curie, 7th Framework Programme, European Commission, con vigencia de 2014 a 2018 y dirigido por la profesora Beatriz Padilla.

3 La noción de discurso manejada en este trabajo es la de discurso en tanto que práctica discursiva.
} 
función de los contextos. En España, como en otros tantos lugares, la corrección política y la sanción social opera y media para que no emerjan en demasía o se evidencien lógicas de funcionamiento del racismo de corte biologicista y/o explícito (Olmos-Alcaraz, 2009; Idem, 2015). En su lugar tenemos un racismo de corte cultural y diferencialista (que parece "no jerarquizar" sino "separar"), que habla de etnias - de forma eufemística-y de culturas:

El desplazamiento que hacen numerosos autores pertenecientes a esta corriente, consiste en hablar de etnicidad para (...) "exorcizar el mal del racismo", [pero esto] no es más que una impostura, ya que el concepto utilitario de "etnia", si bien nos permite prescindir del término "raza", en realidad deja un espacio más o menos amplio para los factores físicos, que se combinarían con rasgos culturales para caracterizar a los llamados grupos "étnicos". (Wiewiorka, 1992, p. 91)

Pero que sigue ejerciendo su poder y funcionando desde dentro de las instituciones. Entonces iqué sucede cuando el racismo es vehiculado a través de las RSV? Contamos con algunos estudios al respecto: investigaciones que han abordado cómo es la exposición a contenidos racistas en función de las características personales de los usuarios de las RSV (Costello et alii, 2016); investigaciones sobre las distintas reacciones a la exposición e impacto de/a esos contenidos (Rauch, Schanz, 2013); investigaciones que han indagado en casos concretos de episodios racistas en RSV (Arriaga, 2013; Cisneros, Nakayama, 2015; Ferrándiz, Ibáñez, Espinosa, 2011; Garcia, Abrahão, 2015; Miró, 2016); o investigaciones que han detectado tipos específicos de racismo -islamófobo, anti-árabe, racismo sexista, post-racismo- (Alcántara, Ruíz, 2017; Awan, 2016; Khosravinik, Zia, 2016; Mason, 2016; Dubrofsky, Wood, 2014) en redes. Sin embargo el comportamiento del racismo en estos contextos virtuales es aún un campo de estudio por explorar, sobre todo en lo relativo a las peculiaridades que las características de las RSV pueden imprimir en lógicas tradicionales de funcionamiento del mismo. Ahondemos un poco más en este asunto.

Algunas de las características de las RSV (extensibles a internet en su conjunto, pero especialmente relevantes en Facebook o Twitter) son la "inmediatez", la "difusión" y la posibilidad de "anonimato".

La inmediatez en la comunicación y la gran capacidad de propagación de la información que propician las RSV, imprimen especificidad al análisis de los discursos-prácticas diferenciadoras y racistas, porque las posibilidades de llegar a más personas se multiplican exponencialmente con respecto a las interacciones producidas cara a cara o con respecto a los medios de comunicación tradicionales. Estar permanentemente conectado a internet es ya una realidad, y la participación en RSV es la forma más habitual de transitar estos espacios. Ello, conjuntamente con la cada vez mayor penetración de la tecnología de los dispositivos Smartphone -dotados de gran autonomía y 
portabilidad, lo cual supone un "paso significativo en el proceso de socialización de estas tecnologías" (Romero, 2014, p. 19)-, hace que la inmediatez (incluso más bien deberíamos hablar de un "permanente directo") sea una característica estructural de las RSV. Cuando pensamos en inmediatez, automáticamente desaparece, o cómo mínimo se relaja, la "corrección política": la misma no es posible sin planificación, programación y previsión.

Por su parte, la difusión tiene que ver con la capacidad de interactividad que propician las redes sociales a partir de lo que se conoce como "convergencia mediática" (Jenkins, 2008), en tanto que transformación del uso tradicional de los medios de comunicación debido a las crecientes interrelaciones y conexiones establecidas por los usuarios de los mismos. Las RSV son espacios públicos, abiertos, son como las ágoras del siglo XXI (Berlanga, García, 2015). Y eso supone, por ejemplo, que las RSV brinden la posibilidad de poner en contacto a todos los lectores de un diario ${ }^{4}$. Pero hablar de difusión es, por supuesto, hablar también de las personas a las que llega la información. Para ello es importante conocer la viralidad de los comentarios, los "me gusta" y la cantidad de veces que son compartidos. Y por último, pero sin querer agotar la definición de esta característica de las RSV, tendríamos que considerar la durabilidad de la información contenida, ya que los comentarios permanecen en la red después de la publicación de las noticias. En este sentido sería ingenuo afirmar que podemos conocer con exactitud la influencia e impacto que pueden tener los comentarios vertidos en una de estas RSV, porque entre otras muchas cuestiones, los contextos siempre van a imprimir particularidades. Aún más, entiendo, es difícil conocer al respecto cuando el análisis sobre los mismos es para estudiar representaciones sociales y su influencia sobre la construcción de imaginarios sociales. No obstante contamos ya con algunas investigaciones que defienden la investigación en RSV como una forma de prospectiva social que puede hacer las veces de barómetro de opinión, pudiendo tomar con ello el pulso a la opinión pública de una sociedad determinada (Congosto, 2014).

Finalmente, con respecto al anonimato, decir que es una de las características más importantes que definen a internet en su conjunto, pero es especialmente relevante en la investigación con RSV, sobre todo cuando se trata de analizar lógicas de funcionamiento del racismo. El anonimato en las intervenciones se relaciona con la construcción de una identidad digital "a medida" que se proyecta a través de seudónimos, alias, avatares o apodos (nicknames), dando lugar en ocasiones al surgimiento de personajes retóricos al más puro estilo de los

\footnotetext{
${ }_{4}$ En el caso concreto estudiado, los discursos analizados son debates que surgen en Facebook a partir de la publicación de una noticia en prensa, en este caso sobre "la inmigración en el paso fronterizo de Melilla". Es como si después de leer la prensa en la cafetería donde desayunamos habitualmente comentásemos la noticia con nuestros acompañantes o con otras personas allí presentes, pero multiplicado por cien o incluso por mil, o decenas de miles.
} 
clásicos discursos políticos (Pujante, 2010), pero en este caso a través de "microdiscursos". En esos casos la persona "se crea [a sí misma como] un personaje retórico con unas características determinadas (...) anulándose así la persona real (...) [y] muchas veces el personaje creado no es sino el modo de verse el propio emisor del discurso" (ibidem). Ello hace que la persona preserve siempre que quiera su intimidad, su verdadera identidad y personalidad, prevaleciendo el personaje. O todo lo contrario: que las muestre sin tapujos expresando ideas, opiniones, juicios sin temor hacia la sanción social "cara a cara". Bañón, nos dice lo siguiente sobre el anonimato en relación a la red de redes en general:

La primera de esas características posibles es el anonimato, una circunstancia comunicativa que pudiera favorecer los usos verbales más provocativos sintiéndose amparado en una identidad oculta y, por consiguiente, en una 'imposibilidad' para identificar responsabilidades. (Bañón, 2010, p. 657)

Algo perfectamente aplicable a la comunicación a través de las RSV, y que condiciona de gran manera-como mostraré a lo largo del artículo- los discursos que se producen sobre inmigración y racismo en los soportes analizados.

\section{Diseño metodológico}

El artículo muestra una investigación de carácter descriptivo-interpretativo, donde se ha observado la repercusión (entendida como "reacción" en forma de comentarios generados) en Facebook de una noticia publicada en prensa ${ }^{5}$ sobre el paso de personas inmigrantes en la frontera de Melilla ${ }^{6}$. El objeto teórico de estudio del trabajo es, recordemos, estudiar las representaciones de alteridad sobre las migraciones y las nuevas lógicas de funcionamiento del racismo, a partir de este estudio de caso concreto.

Para ello se registró un día de actividad ${ }^{7}$ de las dos páginas de Facebook de dos diarios de tirada nacional (El País y El Mundo) ${ }^{8}$ en relación a la publicación de las siguientes noticias:

1) "Unos 300 inmigrantes entran en Melilla en un salto masivo a la valla. Cerca de 500 sin papeles han intentado entrar en la ciudad. Los que lo han logrado han llegado al grito de "victoria" al CETI" -en el caso de El País9-.

5 Este trabajo se hace eco, sin suponer su objeto teórico de estudio, del creciente interés por parte de la comunidad científica por estudiar las relaciones entre los medios de comunicación tradicionales y los medios sociales, dada la constatada falta de independencia y retroalimentación de ambos soportes en el modelo de comunicación-información del momento actual (Cf. Castells, 2008).

6 Ciudad autónoma fronteriza española situada en África, en el norte de Marruecos.

7 El 18 de marzo de 2014.

8 Los diarios escogidos para realizar el estudio son los de mayor tirada del país (exceptuando los diarios deportivos). El Mundo es un medio ideológicamente de derechas; El País, tradicionalmente de izquierda, o centro izquierda, en la actualidad está virando y acercándose al liberalismo o lo que viene definiéndose como "neoconservadurismo".

9 Cf. <http://elpais.com/hemeroteca/elpais/2014/03/18/m/portada.html>. 
2) "Unos 300 inmigrantes entran en Melilla en un salto masivo a la valla. Los subsaharianos han aprovechado la densa niebla para realizar una entrada masiva en la ciudad autónoma, la séptima en lo que va de año" -en el caso de El Mundo ${ }^{10}$.

Las fuentes de obtención de datos han sido, por un lado, las propias noticias publicadas en los citados diarios; y, por otro, las páginas de Facebook de los mismos, de las cuales se extrajeron los comentarios que generó la unidad informativa desde su publicación hasta las $21.00 \mathrm{~h}$ de la jornada observada. La noticia comentada en el Facebook de El País recibió hasta ese momento 162 comentarios y 721 "me gusta"; mientras que la de El Mundo tuvo 210 comentarios y 357 "me gusta". La muestra analizada ha sido, por lo tanto, de 372 comentarios, si bien muchos de ellos no fueron representativos para los objetivos de la investigación. Es por ello que sólo se tuvieron en cuenta para el estudio aquellos relativos a la construcción de alteridad y lógicas de funcionamiento del racismo.

A continuación se realizó análisis de contenido para identificar los principales tópicos y las estrategias discursivas de construcción de la diferencia predominantes; y con ello proceder en la interpretación de las lógicas de funcionamiento del racismo. El tratamiento de los datos se realizó con NVivo, a partir de una plantilla de categorías temáticas, elaborada a partir de un procedimiento inductivo tal y como nos dictan las bases de la teoría fundamentada.

En la Tabla 1 se recogen los principales tópicos encontrados, distinguiendo en primer lugar, entre los más recurrentes de la página en Facebook del diario El País; y, en segundo lugar, los más habituales en la respectiva página del periódico El Mundo. Esta exposición por separado nos permitirá una posterior comparación entre ambos medios, y comparación entre los discursos de las audiencias más recurrentes en cada uno de ellos.

\section{Tabla 1. Principales tópicos sobre la inmigración en las redes sociales virtuales analizadas}

\begin{tabular}{l|l}
\hline \multicolumn{1}{c|}{ Página de Facebook del diario El País } & \multicolumn{1}{c}{ Página de Facebook del diario El Mundo } \\
\hline 1. El “umbral de tolerancia” & 1. Refuerzo de las fronteras \\
\hline 2. Reivindicación del derecho a migrar & 2. El “umbral de tolerancia” \\
\hline 3. Causas de la inmigración & $\begin{array}{l}\text { 3. La inmigración como carga social/competencia } \\
\text { por recursos sociales }\end{array}$ \\
\hline 4. Racismo/rechazo a la inmigración & 4. El migrante como enemigo \\
\hline
\end{tabular}

Fuente: elaboración propia

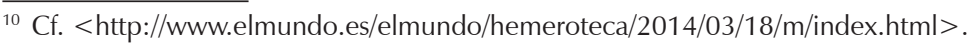


A continuación se muestran los resultados obtenidos entorno a los tópicos prevalentes detectados.

\section{Resultados: "saltos y asaltos" en la frontera o el debate sobre las migraciones en España}

Los sucesos que motivaron las noticias (y su eco en RSV) analizadas en este trabajo, tienen que ver con la entrada de población migrante en situación administrativa irregular a través de la ciudad fronteriza de Melilla. Se trató, stricto sensu, de cientos de personas intentando entrar al mismo tiempo en territorio español a través de un valla de alambrada fortificada de unos 16 kilómetros de largo, con hasta 6 metros de altura, coronada con una concertina de cuchillas en la parte más alta. Esta forma de entrada irregular al país por parte de personas procedentes de países africanos comienza a producirse (paralelamente a la cobertura mediática de la misma) a finales de los años dos mil. Hasta entonces la vía marítima (a través de pequeñas embarcaciones: pateras, cayucos, etc.) había sido la más habitual y la más "mediatizada" (Olmos-Alcaraz, 2013) con respecto a este tipo de migraciones. En los días en los que se producen los hechos, los medios de comunicación en general $-y$ las redes sociales en particular- se inundan de debates, tertulias, intervenciones de políticos, etc., sobre el fenómeno migratorio, que podemos resumir bajo el lema "Inmigración sí o inmigración no". Es decir, el clamor general fue discutir sobre si España estaba, o no, a favor de los movimientos migratorios, y en qué términos y condiciones (Olmos-Alcaraz, Bouachra, 2014). Es por ello que resulta realmente interesante analizar los argumentos y tópicos más recurrentes esbozados en ese momento para pensar sobre las representaciones de alteridad sobre las migraciones y las nuevas lógicas de funcionamiento del racismo. Siendo así, como podemos observar en la Tabla 1 , en las dos redes sociales analizadas, cuando se discute sobre la inmigración, el discurso oscila principalmente entorno a la idea de la existencia de un "umbral de tolerancia" del país. En el caso de la página de Facebook de El País además, y en segundo lugar, se habla del derecho a migrar (Derechos Humanos) y de las causas de la inmigración. En menor medida se emiten discursos racistas y de rechazo explícito hacia la inmigración. En el caso de los discursos encontrados en la página de Facebook de El Mundo, los cuatro tópicos más recurrentes encajan dentro de lo que Zapata-Barrero (2007) denomina "discursos reactivos" sobre la inmigración, discursos con una oposición clara y explícita al fenómeno migratorio, y que están en la línea de lo que se conoce como "el nuevo conservadurismo" (ibidem), y en ocasiones con tintes racistas explícitos.

La noticia que publica el diario El País se inicia como sigue:

Más de 530 inmigrantes lograron entrar en territorio español tras saltar el vallado fronterizo de Melilla en enero y febrero pasados. Eso supone el triple de la media media mensual (...). Fuentes del Ministerio del Interior 
no ocultan su preocupación por este hecho que, en su opinión, viene a corroborar la "fortísima" presión migratoria que hay sobre Melilla y Ceuta. ${ }^{11}$

En la misma se describen cómo son los hechos, que se califican de "salto a la valla", y se pone de manifiesto la preocupación de las autoridades por el volumen de personas que está tratando de migrar por esta vía. En la noticia que publica El Mundo puede leerse lo siguiente:

Se trata del asalto a la valla más multitudinario de su historia, ya que hasta ahora el más numeroso se produjo el 3 de octubre de 2005, cuando 350 inmigrantes lo consiguieron en una época en la que la alambrada medía sólo tres metros y carecía de las medidas de seguridad que tiene ahora. (...). Fuentes policiales afirman que ha sido un asalto muy violento, en el que los inmigrantes han lanzado piedras a los agentes que trataban de impedirlo a ambos lados de la frontera. ${ }^{12}$

A diferencia de la cobertura que ofrece El País, en esa ocasión los hechos se califican de "asalto" (no de "salto", apelativo más neutro); y se describen como muy violentos, poniendo el énfasis en las formas y no en los causas que motivan los hechos.

Veamos a continuación los tópicos más recurrentes encontrados en cada una de las respetivas páginas de Facebook analizadas.

\subsection{Discursos sobre el fenómeno de la inmigración en la página de Facebook del diario El País}

\section{El "umbral de tolerancia"}

La noticia escogida para realizar este trabajo ha condicionado sin duda la emergencia de unas temáticas, y no otras, entorno al fenómeno de la inmigración. El hecho noticiado era, como comentaba, el paso fronterizo de inmigrantes en situación administrativa irregular a través de la valla de la ciudad de Melilla. Es posible que justamente por ello en ambas páginas las personas participantes en los debates discutieran principalmente sobre lo que podemos definir como "umbral de tolerancia". Véase el siguiente ejemplo ${ }^{13}$ :

\section{Ejemplo 1}

Por cierto, no critico ni de lejos a los inmigrantes africanos que nos llegan. Estoy de acuerdo contigo en que son gente que merece lo mejor. En lo que no estoy de acuerdo es que tengamos que quedarnos por narices con todo el que quiera vivir aquí, cuando desgraciadamente ya tenemos

\footnotetext{
11 El País, op. cit.

${ }^{12}$ El Mundo, op. cit.

13 Todas las citas incluidas en este artículo serán reproducidas tal cual fueron escritas en las páginas de Facebook analizadas, a excepción de cuando se parafrasean. Eso implica que cuando aparecen de manera literal no se han modificado, conteniendo las erratas léxico-gramaticales tan características de la comunicación a través de redes sociales virtuales.
} 
6 millones de parados ¿Has leído mi comentario al respecto? No se puede absorber más población sin medios de vida. ¿Por qué no cualquier país con menos paro y más PIB hace campañas de acogida para desheredados? ¿Por qué no promueves en tu país que acoja a los cientos, miles, que llegan a España? A lo mejor es porque también de tu país salen a millares, como a millares llegaron aquí en los tiempos de la burbuja.

Cuando se habla del "umbral de tolerancia" se evoca un "punto imaginario, crítico, a partir del cual una sociedad no puede absorber un mayor número de inmigrantes so pena de debilitar notablemente su capacidad de tolerancia o de acelerar su riesgo de desintegración" (Aierdi, 2007, p. 299). En el fragmento anterior, la persona que habla incide en un matiz económico para avalar sus argumentos: España no puede absorber más población "sin medios de vida". Este tipo de discursos suponen un ejemplo prototípico de rechazo a la inmigración por cuestiones económicas, lo cual socialmente puede parecer "menos sancionable" que otras formas de rechazo y discriminación más abiertas y/o por otros factores. La alocución que inicia el esbozo de la idea ("no critico ni de lejos a los inmigrantes africanos que nos llegan"), construida en forma de disclaimer o exculpación anticipada (Van Dijk, 2009) al suponer una auto-construcción positiva, completa la sutileza y corrección política con que se emiten los argumentos que aparecen a continuación: "no estoy de acuerdo (...) que tengamos que quedarnos por narices con todo el que quiera vivir aquí".

Mucho se ha escrito sobre dicho "umbral de tolerancia", pero sigue siendo una quimera tratar de establecer una tasa, un porcentaje o un número que dé forma y entidad al mismo en una sociedad/espacio en concreto. Sin embargo es una idea socialmente muy extendida y mediáticamente muy explotada, de tal modo que sirve tanto para expresar preocupación por la gestión de los flujos como para negarse a la existencia de los mismos (Aierdi, 2007). En el caso citado, se está usando para lo segundo.

\section{De las reivindicaciones del derecho a migrar y la inevitabilidad de los flujos migratorios}

El segundo gran tópico que emerge al analizar los comentarios vertidos en la página de Facebook de El País, tiene que ver con la invocación a la aplicación de los Derechos Humanos para evitar que sucedan situaciones tan dramáticas como las narradas en las unidades informativas objeto de estudio en este trabajo. Siendo así, encontramos que un volumen importante de los comentarios eran del siguiente tipo:

Ejemplo 2

ningun ser humano es ilegal, ilegal es violar los derechos humanos!!! 


\section{Ejemplo 3}

pobre gente y encima algunos echandoles la mierda encima... yo me cago en la politica, en las banderas, en las fronteras, en las cuchillas de las vallas ... el ser humano esta por encima de cualquier otra cosa.

Se trata de narrativas de denuncia de la situación extrema que viven las personas que se ven empujadas a migrar en esas condiciones. El ejemplo 2 se hace eco de la consigna de tantas ONG que trabajan en la defensa de los derechos de las personas migrantes con vocación de des-criminalizarlas: una persona nunca puede ser "ilegal", es su "situación administrativa" la que, en todo caso, puede ser "irregular"; pero además pone de manifiesto que el trato que los Estados dan a las mismas -justamente por estar en esa situación de vulnerabilidad de derechos- sí que supone una violación de los Derechos Humanos. Como sabemos el derecho a emigrar está avalado por el artículo 13 de la Declaración Universal de Derechos Humanos ${ }^{14}$, pero no así el derecho a inmigrar que quedaría en manos de la normativa interna de cada Estado. Cabría preguntarse en este sentido ¿̇sería un exponente de racismo institucional el que un Estado/grupo de estados no reconociese la contraparte del derecho a migrar que queda incompleta en la Declaración Universal de los Derechos Humanos $?^{15}$ ¿Sería este un ejemplo de discriminación y exclusión sin que exista una intención o propósito explícito por parte del grupo dominante? (Carmichael, Hamilton, 1999). Y lo que nos interesa más para los objetivos de este trabajo zes esta realidad la que legitima que se sostengan discursos racistas sin el miedo a ser sancionados socialmente y/o jurídicamente?

\section{Causas de la inmigración}

Dentro de los tópicos prevalentes vertidos en la página de Facebook de El País encontramos también discursos de personas que tratan de buscar explicaciones a por qué se producen las migraciones; o a por qué se producen las migraciones de una determinada manera y no de otra: en condiciones extremas, sin ninguna cobertura ni seguridad, a través del paso clandestino saltando vallas fortificadas... arriesgando la vida, en definitiva. Son discursos como el que sigue:

14 1) Toda persona tiene derecho a circular libremente y a elegir su residencia en el territorio de un Estado; 2) Toda persona tiene derecho a salir de cualquier país, incluso del propio, y a regresar a su país.

${ }^{15}$ J. De Lucas (1998) nos dice al respecto que: "El principio general [de la libre circulación] topa frontalmente con la soberanía de los Estados y especialmente con su concepción de soberanía absoluta, lo que hace que (...) se limite el derecho de libre circulación y residencia siempre por razones poco concretas, arbitrarias y mal definidas de «seguridad nacional», «interés general», «orden público» y «salud o moral públicas»" (ibidem, p. 237). Y sugiere una "redefinición del concepto de libertad de circulación y residencia para poder delimitar los derechos «soberanos» de los Estados (...) y evitar que la violación de los derechos y libertades en el ejercicio de este derecho sean la norma y no la excepción" (ibidem, p. 237). 


\section{Ejemplo 4}

Hasta que no se consoliden políticas de desarrollo en países en los que mueren de hambre y especialmente en África, continente olvidado para dar pero no para expoliarles todos sus recursos, el problema se irá agravando ya que el instinto de sobrevivencia no lo elimina nadie!!!

Narrativas de este tipo suponen formas de interpretar los hechos más allá de los mismos, con cierto carácter reflexivo y crítico, pero con una visión desarrollista. También alterizan a las poblaciones migrantes, aunque de otro modo, dado su cariz paternalista. Homogeneizan la diversidad de diversidades (Vertovec, 2007; Padilla, Azevedo, Olmos-Alcaraz, 2015; Padilla, OlmosAlcaraz, Azevedo, 2018) y construyen al "otro" migrante (africano, en este caso) como "sub-desarrollado" (Escobar, 1996), necesitado de la intervención de políticas económicas procedentes del "mundo civilizado" erigido de nuevo como el único capaz de revertir la situación; pero al mismo tiempo ponen sobre la mesa y denuncian de manera muy clara la responsabilidad de los países más ricos en la situación de extrema desigualdad y colonialidad actual (Quijano, 2000; Grosfoguel, 2012) sobre la que se sustentan y tienen lugar los movimientos migratorios contemporáneos.

\section{Racismo/rechazo a la inmigración}

Los discursos abiertamente racistas y de rechazo a la inmigración en la página de Facebook de El País no son los más frecuentes del corpus analizado. No obstante también están entre los más visibles, junto con los comentados anteriormente. Además destacan por su crudeza y violencia, tanto explícita como simbólica. Analicemos los siguientes:

\section{Ejemplo 5}

no son 300 son 500 pero esto manda huevos los españoles emigrando acia suiza y europa por k no tenemos para vivir y estos vienen sin nada y asta cobran ayudas manda huevos k estuve en el inen y solo abia estrangeros pidiendo la ayuda pero $\mathrm{k}$ mierda pasa carajo.

\section{Ejemplo 6}

A cagar a la via...ya somos mayoria los que pensamos lo contrario no te has dado cuenta? y si les tiran piedras y atacan a palos, joder que tiren de pistola. ¿o instalamos un puerta giratoria? Cansados de pijiprogrés!

El ejemplo número 5 vuelve de nuevo al argumento económico, se trata de una queja explícita sobre el cobro de ayudas de carácter social por parte de la población inmigrante, lo que -se argumenta- se conecta con la imposibilidad de que la población autóctona necesitada cobre esas mismas ayudas. El ejemplo número 6, por su parte, pide que se usen las armas ("que tiren de pistola") contra los migrantes que desean entrar en territorio español, ironiza de manera desafiante con la posibilidad de abrir las fronteras ("¿instalamos una puerta 
giratoria"?), y descalifica a quienes tienen un discurso no afín al propio con el apelativo "pijiprogres"16. Todo ello nos deja entrever ciertas características de quienes hablan: no se identifican con una posición económica y social acomodada y no se identifican como progresistas. Pero no deben importarnos las identificaciones personales, sino las posibles conexiones que tengan las mismas con estructuras ideológicas institucionalizadas. A este respecto, y volviendo a trabajo de Zapata-Barrero (2007), podríamos ubicar este tipo de discursos claramente reactivos con respecto al fenómeno migratorio dentro de lo que se conoce como "nuevo conservadurismo".

\subsection{Discursos sobre el fenómeno de la inmigración en la página de Facebook del diario El Mundo}

\section{Refuerzo de las fronteras}

En el caso de los comentarios en la página de Facebook del diario El Mundo, prevalecen sobre el resto los relativos a la fortificación de las fronteras para evitar la entrada de migrantes:

\section{Ejemplo 7}

La violaciòn de fronteras y su resguardo es una prioridad. Nada de lo que esta sucediendo en Ceuta Melilla es ajeno a Marruecos, que solapadamente lo consiente y lo propicia. Es lamentable, pero tenemos que endurecer la politica fronterizay si es necesario pasarla a la jurisdiccion militar con todas sus consecuencias.

\section{Ejemplo 8}

Pero como se puede permitir eso, que se haga cargo la legion de la frontera y todos esos ilegales de vuelta a marruecos

En el discurso número 8 se apela a la necesidad de que el ejercito ("la legión $n^{\prime 17}$ ) se haga cargo del asunto. Es decir, se expresa un deseo por fortificar las fronteras a través de un proceso de militarización del control de los flujos migratorios, lo que no supone un endurecimiento sin más, sino que redunda en la construcción de una idea de las migraciones y los inmigrantes como amenaza, como enemigos y como invasores de los que hay defenderse en una situación "de guerra". Esta representación de alteridad total se refuerza cuando el hablante se refiere a quienes tratan de entrar a suelo español como "esos ilegales". No deben sorprendernos -aunque, desde luego, sí preocuparnos- este tipo de afirmaciones, a pesar de su crudeza y dureza, si las contextualizamos en el marco del aumento de la militarización de las fronteras de toda la Unión Europea, donde gobiernos como el austríaco han

\footnotetext{
${ }_{16}$ Pijo: de $<<$ buena $>>$ posición social/económica; progresista: lo contrario a conservador.

17 Fuerza militar con cuartel solo en varias ciudades del sur de España, entre ellas Ceuta y Melilla. Calificada como de infantería ligera, acción rápida y polivalente.
} 
propuesto y puesto en práctica dispositivos militares para controlar los pasos fronterizos dentro del espacio Schengen ${ }^{18}$ durante la mal llamada crisis de los refugiados ${ }^{19}$. Es decir, que no debe sorprendernos -aunque sí preocuparnos, insisto- que la ciudadanía de a pie repita lo que ya se sostiene desde las instituciones, porque -de nuevo- no es más que hacerse eco de ideas y discursos que han sido esbozados anteriormente por quienes están ostentando posiciones del poder.

\section{A vueltas con el "umbral de tolerancia"}

El tópico del "umbral de tolerancia" aparece también en los comentarios realizados en la página de Facebook del diario El Mundo:

\section{Ejemplo 9}

España no esta para esto ya hay mucha gente eb paro y pasando hambreiademas que vamos hacer? No saben el idioma y no tienen ni estudios ni oficio!!!!!

En la misma línea de la cita analizada más arriba, en esta se alude a razones económicas para poner de manifiesto la incapacidad de España para recibir más flujos migratorios ("España no está para esto"). Se añade en esta ocasión una valoración en negativo, precedida de una pregunta retórica ("que vamos hacer?") a modo de enfatizador, que inferioriza a quienes migran al definirlos por lo que -se entiende- no tienen (cualidades faltantes): no saben la lengua, no tienen estudios, no tienen un oficio. Se trata de una estrategia discursiva de construcción de la diferencia, que consigue realzar las carencias y no los posibles aportes a la sociedad de destino o los procesos de expolio y vulnerabilidad que experimentan quienes migran.

\section{La inmigración como carga social/competencia por recursos sociales}

El tercer tópico que sobresale en los comentarios encontrados en la página de Facebook de El Mundo, enfatiza la idea de que los inmigrantes suponen una sobrecarga para el sistema de atención social español:

\section{Ejemplo 10}

No sera mas logico desviar las ayudas a nuestras familias primero para q tengan alguna forma de comer antes q a los inmigrantes ilegales??... Cuando estemos nosotros bien y en condiciones podremos ayudar a los

\footnotetext{
${ }^{18}$ El acuerdo Schengen solo permite el re-establecimiento de controles de las fronteras interiores de la Unión Europea en "situaciones excepcionales" de corta duración y relacionadas con amenazas a la seguridad nacional y al orden público. El debate está abierto y la Comisión Europea ha presentado varias propuestas de modificación en los últimos años, tratando de modificar el acuerdo para incluir la vertiente migratoria dentro de esa noción de "situación excepcional".

${ }^{19}$ Habría que hablar más bien de una crisis integral de legitimidad la Unión Europea como institución, dado que los refugiados "siempre están en crisis" (Ferrero, 2016, p. 160).
} 
demas... Como se nota q algunos no ven como sus familiares lo pasan mal para poder tirar adelante.

Esta cita se inicia con una pregunta retórica, formulada de forma irónica, que sirve para legitimar la discriminación y la idea de que no se debe dar apoyo social y económico a las poblaciones migrantes que desean entrar e instalarse en España mientras que queden españoles que lo necesiten. Este es el eslogan de varios partidos de ultraderecha españoles, con escasa representación en las instituciones pero con -desgraciadamente- cada vez más calado social. La persona que habla está tratando de visibilizar y hacer patente lo que considera natural: que se practique el favoritismo por el endogrupo; y aprovecha para narrar una experiencia personal ("como se nota que algunos no ven como sus familiares lo pasan mal") para dar más peso a sus argumentos.

\section{El inmigrante como enemigo}

Y por último, en el caso de los comentarios realizados en la página de Facebook del diario El Mundo, destaca la idea del/los inmigrante/s como sujeto/s violento/s, bárbaro/s, delincuente/s... como enemigo/s (Santamaría, 2002), en definitiva. Véanse dos ejemplos al respecto:

Ejemplo 11

Están acostumbrados a utilizar la fuerza, un porcentaje altísimo de ellos han realizado violaciones en su viaje, y la constancia de practicas de canibalismo, lo saben muy bien la Gendarmeria Marroquí.

Ejemplo 12

una imigraçion sin control es algo mui grabe, puede entrar terroristas, asasinos, pedrastas, de todo o tipo, isto ay que tener en cuenta.

Este tipo de discursos, tremendamente diferenciadores y racistas, están entre los más extremos y crudos encontrados. No son los más frecuentes pero, aun así, resulta altamente preocupante que haya personas que alterizan, inferiorizan y deshumanizan de esta manera. $Y$ resulta altamente preocupante porque es posible que la legitimidad necesaria para poder afirmar dichas barbaridades la pueden estar encontrando en algunos discursos políticos ${ }^{20}$; o incluso en formas de proceder -conforme a la ley-que criminalizan a migrantes y refugiados en el momento actual. Ejemplo de ello es la directiva europea "destinada a definir la ayuda a la entrada, a la circulación y a la estancia irregulares" 21 , que permite establecer sanciones a quienes traten de dar socorro

\footnotetext{
${ }^{20}$ Ver este ejemplo: "Hay colectivos que han venido a este país sabiendo que las leyes son permisivas, única y exclusivamente a robar y ser delincuentes", emitido por el político X. García Albiol, del Partido Popular -fuerza política en el Gobierno en el momento de la emisión de dichas declaraciones- (Cf. < https://www.huffingtonpost.es/2015/07/28/frases-racistas-albiol_n_ 7885454.html>.

${ }^{21}$ Cf. Directiva 2002/90/CE del Consejo de 28 de noviembre de 2002.
} 
y ayuden a migrantes que intentan entrar en territorio de la Unión Europea en situación administrativa irregular. Es decir, si la normativa europea entiende que es un delito socorrer a un grupo personas que están a punto de naufragar y morir en el mar ipor qué la ciudadanía de a pie no va a pensar que dichas personas son "terroristas, asesinos, pederastas... y hasta caníbales" dado que no merecen ser salvados de una muerte segura?

\section{Análisis y notas conclusivas}

Como indicaba en el apartado anterior, el análisis realizado mostró la existencia de una representación de las migraciones altamente problematizada, donde además del habitual discurso "políticamente correcto" (Olmos-Alcaraz, 2009; Idem, 2012) encontramos declaraciones abiertamente racistas, poco habituales -aunque preocupantemente en aumento- en discursos públicos en general y en otros medios de comunicación más tradicionales en el contexto español. Ello supone en sí mismo una nueva y/o diferente lógica de funcionamiento del racismo en el contexto considerado: no solo que los discursos racistas son más radicales, sino que también hay más. En otras palabras, las propias características de las RSV parecen estar contribuyendo a que cuestiones socialmente consideradas tabú y de las que apenas se hablaba, estén emergiendo con fuerza y sean cada vez más visibles. Esto es importante porque se corre el riesgo de que esa enorme capacidad de difusión de la información que caracteriza a las redes revierta o haga las veces de amplificador de discursos diferenciadores y racistas.

El léxico usado para hablar de los inmigrantes es -en general- negativo: "ilegales" es el apelativo más usado, aunque también aparecen otros que hacen referencia a cuestiones relacionadas con aspectos económicos: "pobres", "des-heredados", etc.; pero además se han encontrado formas de calificarlos altamente discriminatorias, despreciativas y abiertamente racistas: "violadores", "caníbales", "terroristas", "asesinos", "pederastas". Algunos de los discursos hallados son tremendamente agresivos y crudos, de tal manera que en el contexto analizado sería muy difícil encontrarlos en interacciones cara a cara y/o en audiencias públicas. Aquí es posible ver los efectos de otra de las particularidades señaladas al inicio de este trabajo en tanto que características de la comunicación/información online: el anonimato (voluntario). Pareciera que en RSV no importe lo que se diga, porque es posible ocultar nuestra identidad offline; pero también pareciera que no importa lo que se diga porque la sanción social, en todo caso, no será experimentada con interacciones cara a cara, por lo tanto la percepción de la misma es más débil (Bañón, 2010). Pero la violencia verbal observada también puede explicarse por la inmediatez/rapidez (otra de las características mencionadas más arriba) con que se participa en RSV, ya que a veces la velocidad con que se desarrollan las interacciones por 
escrito no deja espacio para la recapacitación y/o para la planificación de los argumentos (ibidem; Mancera, 2009); no deja espacio para la "corrección política" característica de la comunicación en otros medios y contextos.

Si consideramos el contenido de los discursos, veremos que el tópico que más sobresale en el corpus de datos analizado es el relativo a la existencia de un "umbral de tolerancia" que se teme estar traspasando, y la necesidad de fortificar las fronteras como consecuencia de ello (esto último principalmente con respecto a los comentarios vertidos en la página de Facebook de El Mundo). Comparativamente, los comentarios emitidos en la página de Facebook del diario El País son menos agresivos, problematizadores y/o más sutiles, al tiempo que más diversos en términos ideológicos (se contempla debate en torno a los Derechos Humanos, las causas de las migraciones, etc.); y aunque en ambas RSV encontramos discursos abiertamente racistas, los mismos son más notorios entre los comentarios vertidos en la página de Facebook de $\mathrm{El}$ Mundo. Esto se relaciona con el tono con que los respetivos diarios narran los sucesos, que podríamos resumir con el juego de palabras que ellos mismos nos brindan: "salto" vs. "asalto" a la frontera. Es interesante apreciar también cómo el argumento económico es muy común en ambos espacios analizados, siendo usado por los comentarios más duros realizados en la página de Facebook de El País y sirviendo de base para la construcción de los argumentos diferenciadores y racistas menos contundentes y diferenciadores dentro de la página de El Mundo.

Otra cuestión relevante es que apenas aparecen, en el corpus de datos analizado, intervenciones de personas con experiencias migratorias. En muy pocas ocasiones se ha visto una identificación explícita al respecto. Se reproduce con ello el orden discursivo imperante, tal y como hacen en general los medios (Martín Rojo, 1997) también sucede en el caso de RSV estudiado. Pero además la globalidad de las unidades informativas analizadas y los comentarios a las mismas, construyen a los migrantes como "no sujetos", privados de agencia, de opiniones, de subjetivación... simplemente no están. Esto podría hacernos pensar que las relaciones de poder que vertebran el orden social de los discursos (autorizados/no autorizados) impide que se expresen; y ello los deslegitima para articular sus puntos de vista, defenderse, exigir respeto.

Van Dijk (2009, p. 185) nos dice que el discurso racista "acentúa generalmente Nuestras cosas buenas y Sus cosas malas, y desenfatiza (atenúa, oculta) Nuestras cosas malas y Sus cosas buenas". Este cuadrado "ideológico" -como él mismo lo llama- no se cumple por completo en el corpus de datos analizado. Sí se ha encontrado, sin embargo, una construcción del "nosotros" que no se corresponde con la clásica construcción del endogrupo en positivo. Lo que hay es una identificación con una población en situación de crisis económica y necesitada, que lo está pasando mal por la falta de empleo y ayudas sociales. 
Esa construcción del nosotros sirve para legitimar la discriminación y el racismo, por "nuestra extraordinaria situación de crisis y escasez" -parece sugerirse-, y para exigir a las autoridades que controlen más las fronteras sin importar que ello redunde en el incremento de un tipo de racismo de carácter institucional. Cierto es que Van Dijk habla en casi todos sus trabajos del "racismo de élite" (producido por políticos, medios de comunicación, etc.), y este trabajo no se ha centrado en este tipo de diferenciación social específicamente. El corpus de datos analizados no se compone (o al menos no todo) estrictamente de lo que se viene definiendo como "discursos de élite", ni -por lo tanto- estaríamos hablando de "racismo de élite". Los discursos analizados son producidos por la ciudadanía de "a pie", en este caso lectores de prensa escrita, o seguidores de la misma en sus respectivas páginas de Facebook, comentando el contenido de una noticia -y el suceso narrado en la misma- en RSV. Algunos identificarían este tipo de racismo como "racismo cotidiano", "racismo discursivo" o "infraracismo" (Wieviorka, 1992). En este sentido, independientemente de que no sería pertinente negar la capacidad performativa de todos los discursos (OlmosAlcaraz, 2009; Olmos-Alcaraz, Martín, 2018), sí que es necesario seguir observando las dinámicas y lógicas de funcionamiento de este tipo de discursos cuando se emiten en los medios sociales, porque es justamente esto (su existencia dentro de las RSV) lo que les haría compartir algunas características con los "discursos de élite" y -consecuentemente- conformarse en ocasiones en una especie de "discursos de élite" específicos ${ }^{22}$ : con poder para construir acontecimientos y relaciones sociales; con poder para sostener el statu quo o para promover el cambio social; y ello dada la la difusión, durabilidad, posibilidad de viralidad que otorgan a los mismos las RSV. Nos encontramos así con un panorama de expansión constante de representaciones y discursos (en general, pero también racistas) que llegan fácilmente a mucha gente. Es decir, el racismo ha encontrado una nueva forma de funcionar, expandirse y estar entre nosotros a modo de virus con una alta capacidad infecciosa.

\section{Bibliografía}

AIERDI, Xavier. La traductora de Gerd Baumann. Notas sobre etnicidad y actitudes ante la inmigración en el País Vasco. In: IGARTUA, Juan José; MUÑIZ, Carlos (eds.). Medios de Comunicación, inmigración y sociedad. Salamanca: Ediciones Universidad de Salamanca, 2007, p. 281-310.

ALCÁNTARA, Manuel; RUÍZ, Ana. The framing of muslims on the Spanish internet. Lodz Papers in Pragmatics, v. 13, n. 2, p. 261-283, 2017.

ARRIAGA, Eduard. Racismo y discurso en la era digital: el caso de la revista Hola y los discursos en las redes sociales. Discurso \& Sociedad, v. 7, n. 4, p. 617-642, 2013.

${ }^{22}$ Piénsese en los influencers. 
AWAN, Imran. Islamophobia on Social Media: A Qualitative Analysis of the Facebook's Walls of Hate. International Journal of Cyber Criminology, v. 10, n. 1, p. 1-20, 2016.

BAÑÓN, Antonio. Comunicación destructiva y agresividad verbal en la Red. Notas en torno al discurso sobre las enfermedades raras. Discurso \& Sociedad, v. 4, n. 4, p. 649-673, 2010.

BERLANGA, Inmaculada; GARCÍA, Francisco. Ciberretórica: Aristóteles en las redes sociales. Manual de Retórica en la comunicación digital. Madrid: Fragua, 2014.

CASTELLS, Manuel. Comunicación, poder y contrapoder en la sociedad red (I). Los medios y la política. Telos: Cuadernos de comunicación e innovación, v. 74, p. 13-24, 2008.

CARMICHAEL, Stokely; HAMILTON, Charles V. Poder negro. La política de liberación en Estados Unidos. Madrid: Siglo XXI, 1999.

CISNEROS, J. David; NAKAYAMA, Thomas K. New media, old racisms: Twitter, Miss America, and cultural logics of race. Journal of International and Intercultural Communication, v. 8, n. 2, p. 108-127, 2015.

CONGOSTO, María Luz. Twitter como fuente para conocer la opinión pública. CAC, Cuadernos Artesanos de Comunicación, v. 64, p. 117-142, 2014.

COSTELLO, Matthew; HAWDON, James; RATLIFF, Thomas; GRANTHAM, Tyler. Who views online extremism? Individual attributes leading to exposure. Computers in Human Behavior, v. 63, p. 311-320, 2016.

DE LUCAS, Javier. La Declaración Universal de los Derechos Humanos. Asociación para las Naciones Unidas en España. Barcelona: Icaria, 1998.

DUBROFSKY, Rachel E.; WOOD, Megan M. Posting Racism and Sexism: Authenticity, Agency and Self-Reflexivity in Social Media. Communication and Critical/Cultural Studies, v. 11, n. 3, p. 282-287, 2014.

ESCOBAR, Arturo. La invención del desarrollo. Bogotá: Editorial Norma, 1996.

FERRÁNDIZ, Jimena; IBÁÑEZ, Carolina; ESPINOSA, Agustín. Racismo 2.0: expresiones de prejuicio en las redes sociales virtuales tras las elecciones generales de 2011. Politai: Revista de Ciencia Política, v. 2, n. 3, p. 75-83, 2011.

FERRERO, Ruth. Europa sin rumbo. El fracaso de la UE en la gestión de la crisis de refugiados. Revista de estudios internacionales mediterráneos, v. 21, p. 159176, 2016.

GARCIA, Dantielli Assumpção; ABRAHÃO, Lucília Maria. "Somos todxs Cláudia": A legitimação da violência pelo estado. Linguagem em (Dis)Curso, v. 15, n. 1, p. 47-59, 2015.

GRANADOS, Antolín (ed.). La representación de las migraciones en los medios de comunicación. Madrid: Trotta, 2013.

GROSFOGUEL, Ramón. Sujetos coloniales: una perspectiva global de las migraciones caribeñas. Quito: Abya Yala, 2012.

HINE, Christine. Etnografía virtual. Barcelona: Editorial UOC, 2004. 
JENKINS, Henry. La cultura de la convergencia de los medios de comunicación. Barcelona: Paidós, 2008.

KHOSRAVINIK, Majid; ZIA, Mahrou. Persian nationalism, identity and anti-Arab sentiments in Iranian Facebook discourses: critical discourse analysis and social media communication. Journal of Language and Politics, v. 13, n. 4, p. 755780, 2014.

MANCERA, Ana. Manifestaciones de descortesía y violencia verbal en los foros de opinión digitales de los diarios españoles. Discurso \& Sociedad, v. 3, n. 3, p. 437-466, 2009.

MARTíN ROJO, Luisa. El orden social de los discursos. Discurso, v. 21, n. 22, p. 1-37, 1997.

MARTínEZ, María (ed.). Discourses on Immigration in Times of Economic Crisis: A Critical Perspective. Newcastle: Cambridge Scholars Publishing, 2013.

MASON, Corinne Lysandra. Tinder and humanitarian hook-ups: the erotics of social media racism. Feminist Media Studies, v. 16, n. 5, p. 822-837, 2016.

MIRÓ, Fernando. Taxonomía de la comunicación violenta y el discurso del odio en Internet. Revista de los Estudios de Derecho y Ciencia Política, n. 22, p. 93-118, 2016.

OLMOS-ALCARAZ, Antonia. La población inmigrante extranjera y la construcción de la diferencia. Discursos de alteridad en el sistema educativo andaluz. Tesis Doctoral. Granada: Universidad de Granada, 2009.

OLMOS-ALCARAZ, Antonia. Discurso político e inmigración: análisis crítico de discurso a propósito de la reforma gubernamental realizada al sistema de salud pública en España. Discurso \& Sociedad, v. 6, n. 4, p. 739-758, 2012.

OLMOS-ALCARAZ, Antonia. "Pateras, embarazadas y prostitución": representaciones y discursos sobre la mujer inmigrante en la televisión española. Fonseca Journal of Communication, v. 7, p. 72-99, 2013.

OLMOS-ALCARAZ, Antonia. Análisis crítico de discurso y etnografía: una propuesta metodológica para el estudio de la alteridad con poblaciones migrantes. Empiria. Revista de Metodología de Ciencias Sociales, v. 32, p. 103-128, 2015.

OLMOS-ALCARAZ, Antonia; BOUACHRA, Ouafaa. De saltos y asaltos en las redes sociales: narraciones y discursos en Facebook sobre la inmigración en la frontera de Melilla. Ponencia presentada en el Simposium Internacional de Estudios sobre Discurso y Sociedad (EDiSo). Sevilla: mayo 2014.

OLMOS-ALCARAZ, Antonia; MARTíN, Paula. Retos epistémico-metodológicos en la investigación sobre racismo: de la biología a la cultura, de lo "cuanti" a lo "cuali", de lo discursivo a lo conductual. In: SASSONE, Susana; PADILLA, Beatriz; GONZÁLEZ, Myriam; MATOSSIAN, Benda; MELELLA, Cecilia (comp.). Diversidad, Migraciones y Participación Ciudadana: identidades y relaciones interculturales. Buenos Aires: CONICET-Instituto Multidisciplinario de Historia y Ciencias Humanas, 2018 (forthcoming). 
PADILLA, Beatriz; AZEVEDO, Joana; OLMOS-ALCARAZ, Antonia. Superdiversity and conviviality: exploring frameworks for doing ethnography in Southern European intercultural cities. Ethnic and Racial Studies, n. 38, v. 4, p. 621-635, 2015.

PADILLA, Beatriz; OLMOS-ALCARAZ, Antonia; AZEVEDO, Joana. Etnografías de la convivialidad y superdiversidad: reflexiones metodológicas. Revista Andamios, n. 36, p. 15-41, 2018.

PUJANTE, David. El discurso político como discurso retórico. Estado de la cuestión. 2010. Disponible en: <http://www.cervantesvirtual.com/nd/ark:/59851/ bmct7300 $>$. Consultado: 25.01.2018.

QUIJANO, Aníbal. Colonialidad del poder, eurocentrismo y América Latina. In: LANDER, Edgardo (comp.). Colonialidad del saber, eurocentrismo y ciencias sociales. Buenos Aires: CLACSO-UNESCO, 2000, p. 201-246.

RAUCH, Shannon; SCHANZ, Kimberley. Advancing racism with Facebook: Frequency and purpose of Facebook use and the acceptance of prejudiced and egalitarian messages. Computers in Human Behavior, v. 29, n. 3, p. 610-615, 2013.

RODRÍGUEZ, Luis. Humanidades digitales, ¿una mera etiqueta o un campo por el que deben apostar las ciencias de la documentación? Anuario ThinkEPI, v. 1, p. 37-43, 2013.

ROMERO, Esteban. Ciencias Sociales y Humanidades Digitales: una visión introductoria. CAC, Cuadernos Artesanos de Comunicación, v. 61, p. 19-50, 2014.

SANTAMARIA, Enrique. La incógnita del extraño. Barcelona: Anthropos, 2002.

VAN DIJK, Teun A. Discurso y poder. Barcelona: Gedisa, 2009.

VERTOVEC, Steven. Super-diversity and its implications. Ethnic and Racial Studies, v. 30, n. 6, p. 1024-1054, 2007.

WIEWIORKA, Michel. El espacio del racismo. Barcelona: Paidós, 1992.

ZAPATA-BARRERO, Ricard. Política del discurso sobre inmigración en España: discurso reactivo y discurso pro-activo en los debates parlamentarios. Discurso \& Sociedad, v. 2, n. 1, p. 317-369, 2007.

Recibido para publicación en 15.04.2018 Aceptado para publicación en 01.06.2018 Received for publication in April 15 th 2018 Accepted for publication in June 015t, 2018

ISSN impresso 1980-8585

ISSN eletrônico 2237-9843

http://dx.doi.org/10.1590/1980-85852503880005304 